\title{
Forum
}

\section{In defence of multidisciplinary teams in child and adolescent psychiatry}

\author{
David CotTrell, Senior Lecturer in Child and Adolescent Psychiatry, London \\ Hospital Medical College, London E1 2AD
}

Early in 1992, two articles were published on the subject of multidisciplinary teams in child and adolescent psychiatry. In the first, Mathai (1992) challenges the "accepted multidisciplinary model" as being "unworkable". He comments that in many teams an appearance of multidisciplinary working can hide covert conflicts and goes on to propose that all referrals should be made to the consultant psychiatrist who will then decide to whom these referrals should be allocated within the team.

In the second paper, Silveira et al (1992) describe their experience in providing a unidisciplinary service. They claim that they were able to offer a faster and more efficient service but after $2 \frac{1}{2}$ years, and despite their claims for its effectiveness, they then used additional funding to recruit a new multidisciplinary team. They conclude, if I have understood the paper correctly, that in this new team, with a clearly defined budget and staff recruited on the basis of the psychiatrist taking "professional leadership and managerial responsibility", there will be far fewer of the difficulties associated with multidisciplinary teams.

While I tend to agree with their conclusion that unidisciplinary working is better than "multidisciplinary angst or breakdown" I disagree that the new multidisciplinary team will function well because it has a defined budget and a child psychiatrist with managerial responsibility. Such an arrangement certainly provides more clarity of roles but will not prevent the covert conflicts alluded to by Mathai (1992).

I am also dubious about their claims that the unidisciplinary team worked well. In particular, how did they offer the full range of assessment and treatment options needed to provide a comprehensive service? Dr Silveira and colleagues clearly coped admirably with very difficult circumstances and are to be congratulated on continuing to provide a service which was obviously well received, but I doubt that it was the comprehensive service which could have been provided by a well functioning multidisciplinary team.
The advantages of multidisciplinary teams are many and have been summarised by Ovretveit (1986). These include better service provision, easier access to the service for referrers (who do not have to deal with lots of different professionals), more colleague and peer support for team members, better planning of new developments and better management of different workloads. This latter point is particularly important in the current climate where if different professionals are not working together it will be impossible to agree common priorities. Ovretveit points out that you cannot create teams by just grouping professionals together and calling them teams teams need to be "planned, funded, nurtured and regularly reviewed". He describes four different models for team functioning and stresses the need for agreement about which type is best for the particular professional and client group.

Trowell (1990) has highlighted some of the difficulties of teamwork in child and adolescent psychiatry. These include interdisciplinary rivalry, differences in salary, status and power, personality clashes, different funding sources and policies for different team members, and ownership of the premises. I would add to this list differences in age, experience and training of team members, differences in treatment philosophies and problems around prioritising of cases. Trowell concludes that the advantages of multidisciplinary work for child mental health teams are potentially so great that the hard and sometimes painful work of creating a well functioning team must be persevered with. In discussing possible ways forward she stresses the need to recognise the competence and autonomy of each of the disciplines in the team.

Both the paper by Mathai (1992) and that by Silveira et al (1992) have in common the notion that the consultant must be in charge. However, if the consultant is to receive all referrals and retain overall responsibility then he or she must see and assess all new referrals and then be kept aware of how other professionals are managing each case - it would be no defence in law to claim ignorance of what was 
being done in one's name. Between assessing every new referrals and monitoring the progress of the cases allocated to other team members there would be little or no time to take on therapeutic work of one's own.

In reality, consultants who try to assert this kind of authority over colleagues soon find that they do not have any colleagues. Social workers, for example, are not employed by the NHS, have their own managers, and cannot be instructed by doctors. Local authorities need little enough encouragement to withdraw social workers without doctors antagonising the situation by trying to take control. All over the country clinical psychologists are splitting off from teams where they feel stifled and setting up rival services.

While it is generally agreed that teams need leaders to function optimally (Ovretveit, 1986) this leader does not have to be the doctor. Indeed it is possible to have different leaders for different team functions. The main argument to support the doctor as leader is the one of overall or ultimate 'medical responsibility', but does this idea have any validity?

The Royal College of Psychiatrists (1984) and Rawnsley (1984), reaffirmed support for the multidisciplinary model but acknowledged the problems that such a model can produce. The differences between team functioning at administrative and management levels, and at clinical levels, are highlighted in these papers. However, the list of consultant responsibilities provided includes the statement that "the consultant has a direct responsibility to see that the variety of disciplines caring for patients are co-ordinated ... this implies leadership of the multidisciplinary team".

A later document (Royal College of Psychiatrists, 1986) suggested some shift away from this view. Here the consultant is "clearly seen as clinical leader" in hospital settings but it is acknowledged that different arrangements may be necessary in other 'intermediate' settings e.g. child guidance clinics not administered by health authorities. In such clinics, cases referred to the consultant are said to need some continuing oversight until discharged but cases not referred to the consultant are not seen as part of the consultant's responsibility.

However, the most recent guidance (which is endorsed by the medical defence societies) makes clear that in all child mental health services it is possible for non medical members of the multidisciplinary team to take referrals for assessment and therapy without there being a necessity for doctors to have responsibility for this work (Royal College of Psychiatrists, 1989). The proviso is that it is made clear to referring agencies and to patients that this is the case and that referrers have the opportunity to specifically request that a case be seen by a doctor. It is also necessary to devise a system such that medi- cal conditions are assessed appropriately either by the child's general practitioner or by a medically qualified consultant. While the guidance does not state this explicitly it seems to be referring to outpatient teams. For referrals to in-patient and day patient units in the NHS the issues are more complex. In these units the consultant may still have to retain responsibility-most referrals to these units are to the consultant anyway.

Thus it would seem that there is no legal bar to multidisciplinary teams with open referral systems and with individual team members taking responsibility for their own work. Doctors may wish to be team leaders but there is no legal justification for this having to be the case because of "medical responsibility". Indeed this whole argument may be spurious. The British Psychological Society (1986) in a paper on responsibility in multidisciplinary teams quotes the 'Nodder report' (DHSS, 1980) to the effect that:

"There is, as we understand it, no basis in law for the commonly expressed idea that a consultant may be held responsible for negligence on the part of others simply because he is the 'responsible medical officer': or that, though personally blameless, he may be held accountable after the style of a military commander. A multidisciplinary team has no 'commander' in this sense."

The BPS conclude that it follows that no professional can be held responsible for another professional's actions except in part by negligent delegation or referral. This, of course, might be the case should the consultant seek to stay in charge and retain overall control but is much less likely if open referrals are allowed and the 1989 College guidance followed.

If there is no legal necessity for the doctor to be responsible for all cases referred to a multidisciplinary team why do doctors persist in trying to take charge and, in the process, threaten the viability of the team? Some may be unaware of the most recent College guidance - it is in fact only a half page note which would have been easy to miss. Undoubtedly, medical training prepares doctors for being in charge of patient management. Such a message is probably appropriate for many hospital doctors, including child and adolescent psychiatrists in charge of inpatient units. However, its existence has implications for the training of child psychiatrists, many of whom will be expected to work in out-patient multidisciplinary teams, and perhaps for all doctors. Is part of the problem that some doctors do not know how to work co-operatively with colleagues as members of a team? If so, how do we alter their training?

\section{Conclusion}

One obstacle to the smooth running of multidisciplinary teams is the desire of doctors to be in charge. While there are many models of how such teams 
should be run, most involve some form of power sharing and some doctors are reluctant to enter into this. However, the legal issues of responsibility, often cited to justify the doctor's need to be in control, do not appear to hold water. Given the possible benefits of multidisciplinary teams for our patients we must be prepared to give up some of our authority in order to facilitate a model of care which best meets the needs of our patients.

\section{References}

British Psychological SOCIETY (1986) Responsibility Issues in Clinical Psychology and Multidisciplinary Teamwork. Leicester: British Psychological Society.

MATHAI, J. (1992) Equality in a child and adolescent psychiatry multidisciplinary team. Psychiatric Bulletin, 16, 33.

Ovretveit, J. (1986) Organising Multidisciplinary Community Teams. Middlesex: BIOSS, Brunel University.
RAWNSLEY, K. (1984) The future of the consultant in psychiatry. Bulletin of the Royal College of Psychiatrists, 8, 122-123.

Royal College of Psychiatrists (1984) The responsibilities of consultants in psychiatry within the National Health Service. Bulletin of the Royal College of Psychiatrists, 8, 123-126.

- (1986) The role, responsibilities and work of the child and adolescent psychiatrist. Bulletin of the Royal College of Psychiatrists, 10, 202-206.

- (1989) The responsibility of the child and adolescent psychiatrist in multidisciplinary teams. Psychiatric Bulletin, 13, 521 .

Silveira, W. R., Ballard, C. G., Mohan R. N. C., MCGibBEN, L., et al (1992) Is there a case for 'unidisciplinary working' in child psychiatry? Psychiatric Bulletin, 16, 34-35.

TROWELL, J. (1990) Sustaining multi-disciplinary work. In Child and Adolescent Psychiatry: into the 1990s. (eds. M. Black, J. H. Hendriks \& R. Nicol). London: Royal College of Psychiatrists. pp. 110-112.

\section{'Fly Fishing' by J. R. Hartley: an introduction to psychotherapy}

\section{SAMUel M. Stein, Locum Senior Registrar, University of Cambridge, Department of Psychiatry, Addenbrooke's Hospital, Cambridge CB2 2QQ}

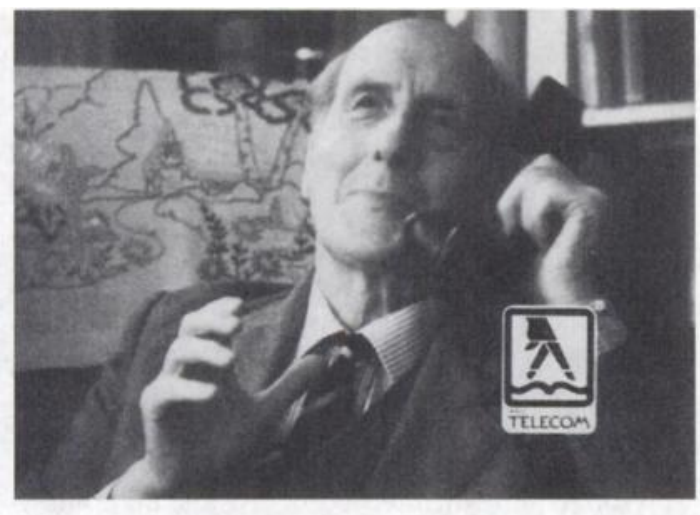

The author J. R. Hartley and his book on fly fishing do not exist in external reality. They are instead a product of the advertising fantasy world, dreamt up to promote the Yellow Pages. This advertisement was at its prime when I was trying to develop a suit- able analogy for teaching medical students and junior doctors about psychotherapy and some of its techniques. When taking a short break in front of the television set, it suddenly struck me just how appropriate this advertisement was. J. R. Hartley himself lends credence to the analogy, while fly fishing as a sport provides an excellent comparison for the art of psychotherapy. Like the fictitious publication in the advert, psychotherapy and its techniques can prove exasperatingly elusive, as they constitute a series of shared internal beliefs and representations which exist largely within the collective mind. I therefore felt that this ambiguous character who is not part of the external real world, yet has a special inner meaning for a wide number of people, seemed like the ideal analogy for describing psychotherapeutic processes.

When testing out this fishing/psychotherapy analogy on friends and colleagues, many automatically assumed that I was talking about coarse fishing. They seemed more accepting of a comparison which 